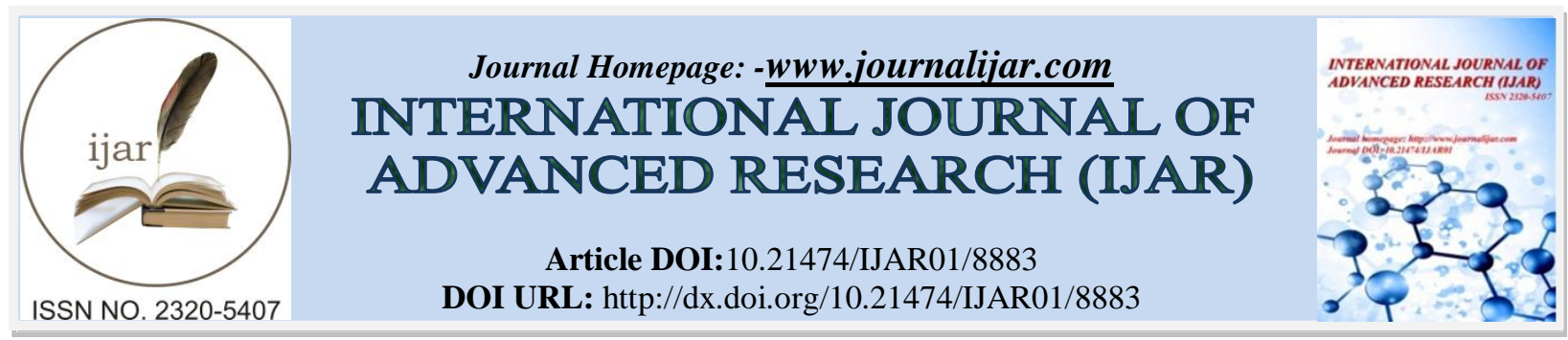

RESEARCH ARTICLE

\title{
CLINICOPATHOLOGICAL STUDY OF NEOPLASTIC LARYNGEAL LESIONS IN A TERTIARY CARE HOSPITAL IN KASHMIR
}

\author{
Dr. Arshi Beg ${ }^{1}$, Prof. Ruby Reshi ${ }^{2}$, Dr. Nisar Hussain Dar ${ }^{3}$, Dr. Farzana Manzoor ${ }^{4}$, Dr. Summiya Farooq ${ }^{5}$ and \\ Dr. Ambreen Beigh ${ }^{4}$ \\ 1.Senior resident, Department of pathology ,Tata Memorial Hospital ,Mumbai. \\ 2.Professor and Head, Department of pathology, Govt. Medical College Srinagar . \\ 3.Associate Professor Department of ENT and H\&NS . Government Medical College, Srinagar. \\ 4.Senior resident, Department of pathology, Govt. Medical College Srinagar . \\ 5.Lecturer, Department of pathology, Govt. Medical College Srinagar
}

\section{Manuscript Info}

Manuscript History

Received: 11 February 2019

Final Accepted: 13 March 2019

Published: April 2019

\section{Abstract}

Background:The larynx is affected by a range of benign and malignant lesions, on account of its unique position in the upper respiratory tract which makes it vulnerable to many noxious stimuli. This study was undertaken to explore clinicopathological parameters in laryngeal cancers as laryngeal lesions are coming up to be the most common head and neck lesions in Kashmir.

Methods :A one and a half year observational study was done(20152017).All layngectomies and biopsies received in the department were studied.

Results: A total number of 68 neoplastic lesions were studied .The neoplastic lesions showed a peak after 50 years. Squamous cell carcinoma was present in $23.5 \%$ cases and was the commonest neoplastic lesion ,Moderately differentiated squamous cell carcinoma was the commonest differentiation(66.7\%). The most common site of involvement was the Glottis $(62.5 \%)$ of cases. Out of the 11 laryngectomies, 3 cases showed perineural invasion, 5 cases showed lymphovascular invasion .

Conclusion:Light microscopy and histopathological examination remains the mainstay and gold standard in diagnosing benign and malignant lesions in larynx.

Copy Right, IJAR, 2019,. All rights reserved.

\section{Introduction:-}

The larynx is affected by a range of malignant tumors arising most commonly from the surface epithelium , malignant tumors can also arise from its associated soft tissue bone and cartilage.. The pathological evaluation of the specimen helps in determining the histopathological type of tumor and accordingly staging the tumor. Moreover, noting the lymphovascular, perineural invasion help to assess prognosis in patients. Due to the limited clinicopathological research done on lesions of larynx and with changing trends and the emergence of laryngeal lesions as the most common head and neck tumors in Kashmir. This study will enlighten us on the occurrence and type of laryngeal tumor in our hospital at Government Medical College, Srinagar. 


\section{Materials and Methods:-}

All cases of laryngeal biopsies and laryngectomies received at Department of Pathology, Government medical College, Srinagar, J\&K were studied.

Demographic data in the form of age, sex, site of biopsy or specimen and other clinical information was0 obtained from the pathology requisition form. History of smoking was asked from the patient. Specimens that were received by the Department of Pathology were properly labelled, numbered and fixed in $10 \%$ buffered formalin. After a detailed gross examination of the specimens, multiple slices were taken from representative sites and processed. Sections taken from paraffin embedded blocks and stained with $\mathrm{H}$ and E.All cases were classified according to WHO histological classification of tumours of the larynx and staged according to TNM classification of larynx. Histopathological prognostic factors such as lymphovascular and perineural invasion, lymph node status were examined.

A one and a half years observational study was done at Department of Pathology, Government medical college Srinagar.(2015-2017)

\section{Results:-}

A total number of 68 neoplastic lesions were studied,which included 56 biopsies and 12 laryngectomies. The neoplastic lesions showed a peak after 50 years. Maximum number of cases were in 60-69 year age group (29.4\%) and $>70$ year age group (30.9\%), followed by, and 50-59 year age group (25\%).[Table 1].

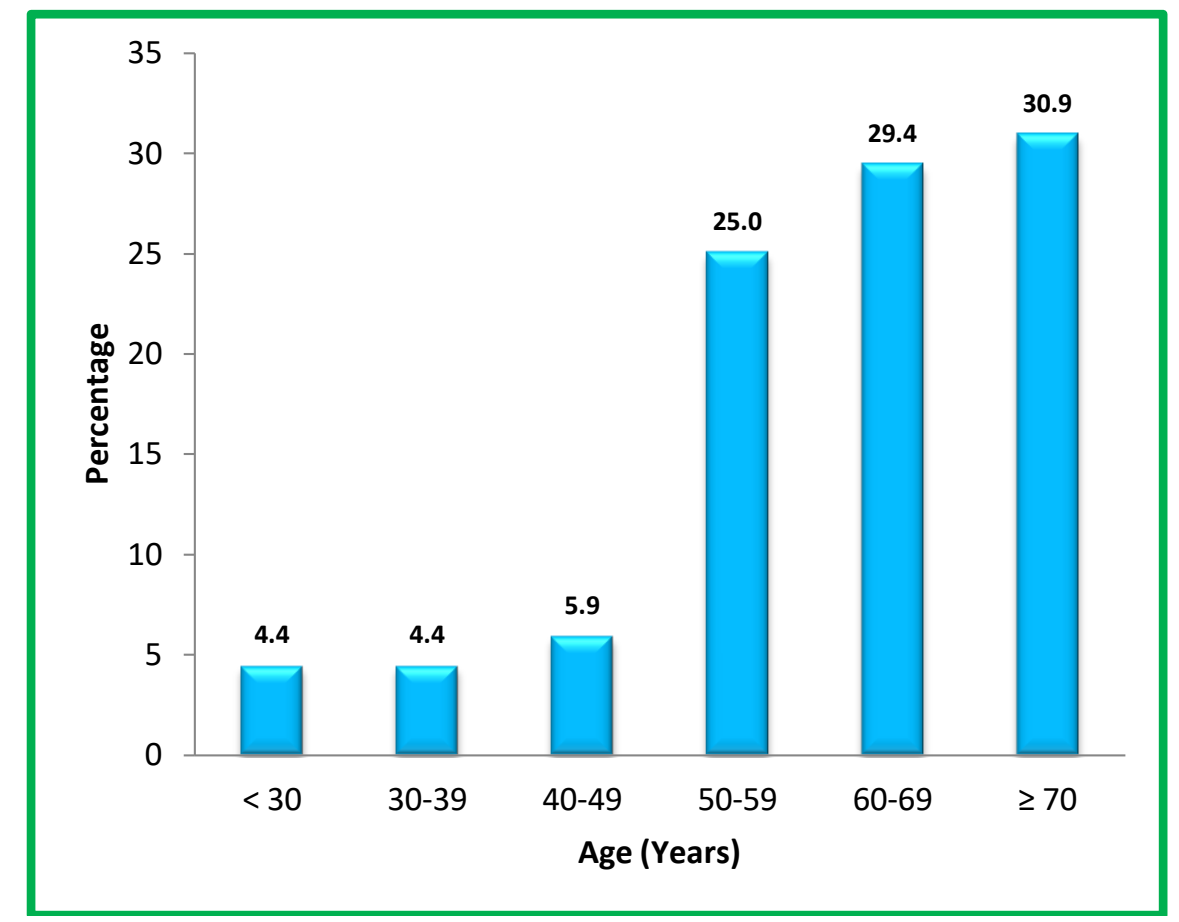

Table 1:-Bar chart showing histopathological pattern of neoplastic lesions as per age.

There was a male preponderance with $91.2 \%$ males and $8.8 \%$ females in the neoplastic lesions. [Table 2] 


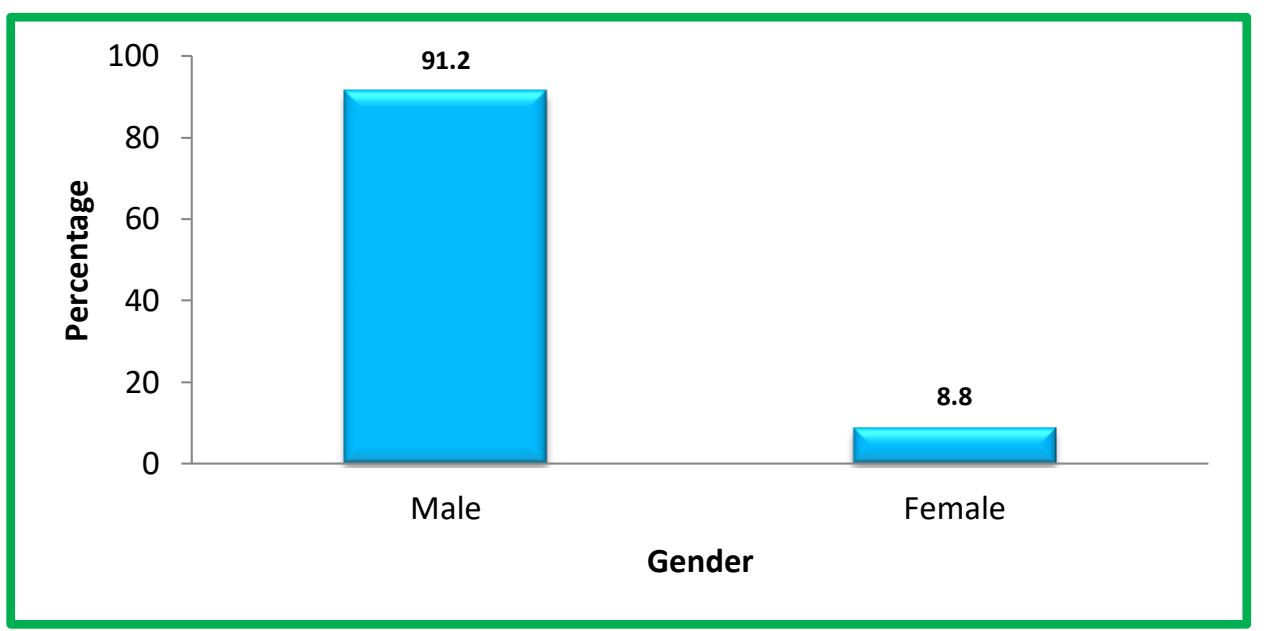

Table 2:-Bar chart showing histopathologic pattern of neoplastic lesions in relation to gender

Neoplastic lesions were common in rural areas (64.7\%) compared to urban (35.3\%).

In the neoplastic group, $94.1 \%$ were smokers and $5.9 \%$ were non-smokers.[Table 3 ]

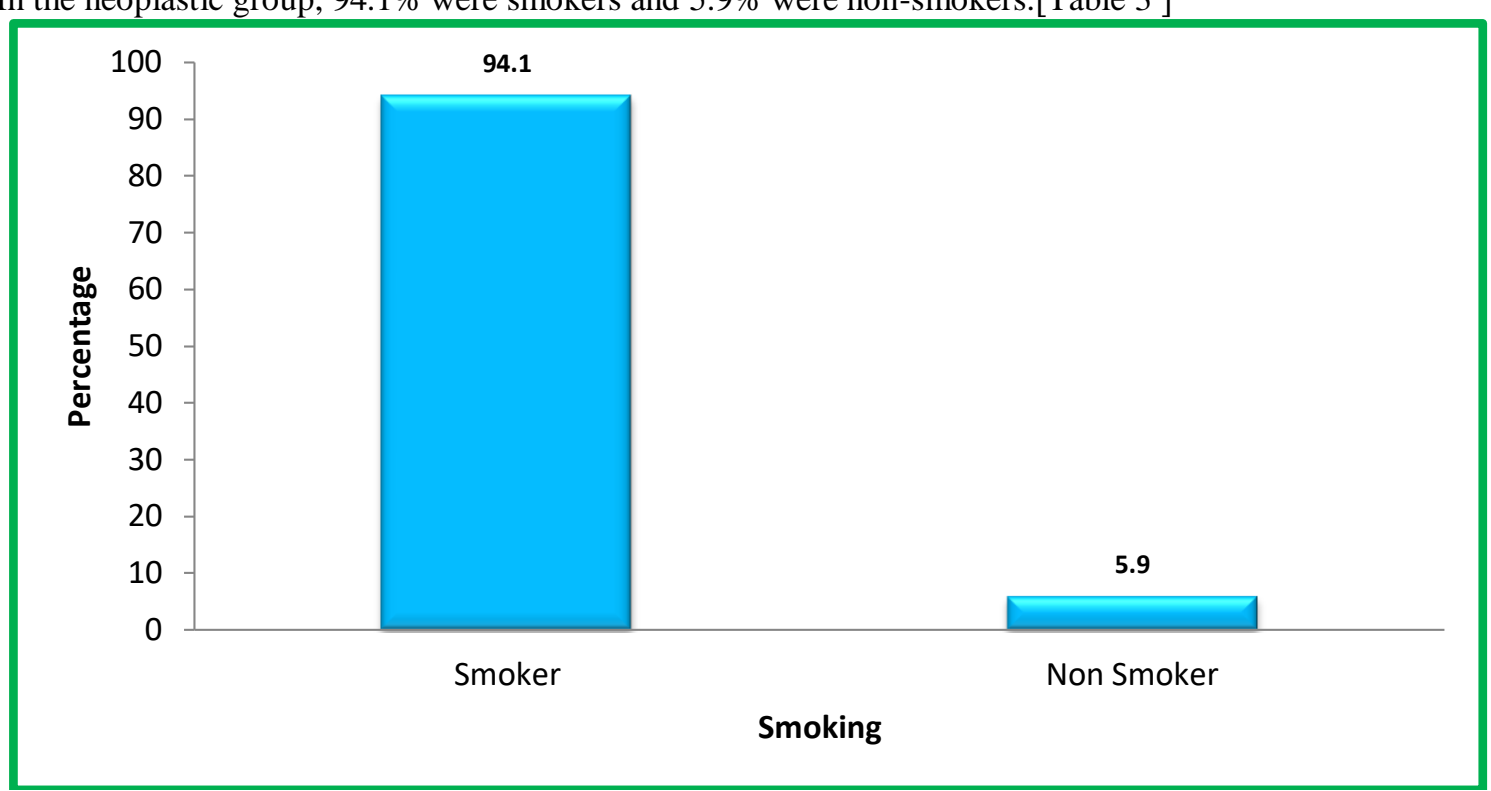

Table 3:-Bar chart showing histopathological pattern of neoplastic lesions as per smoking 


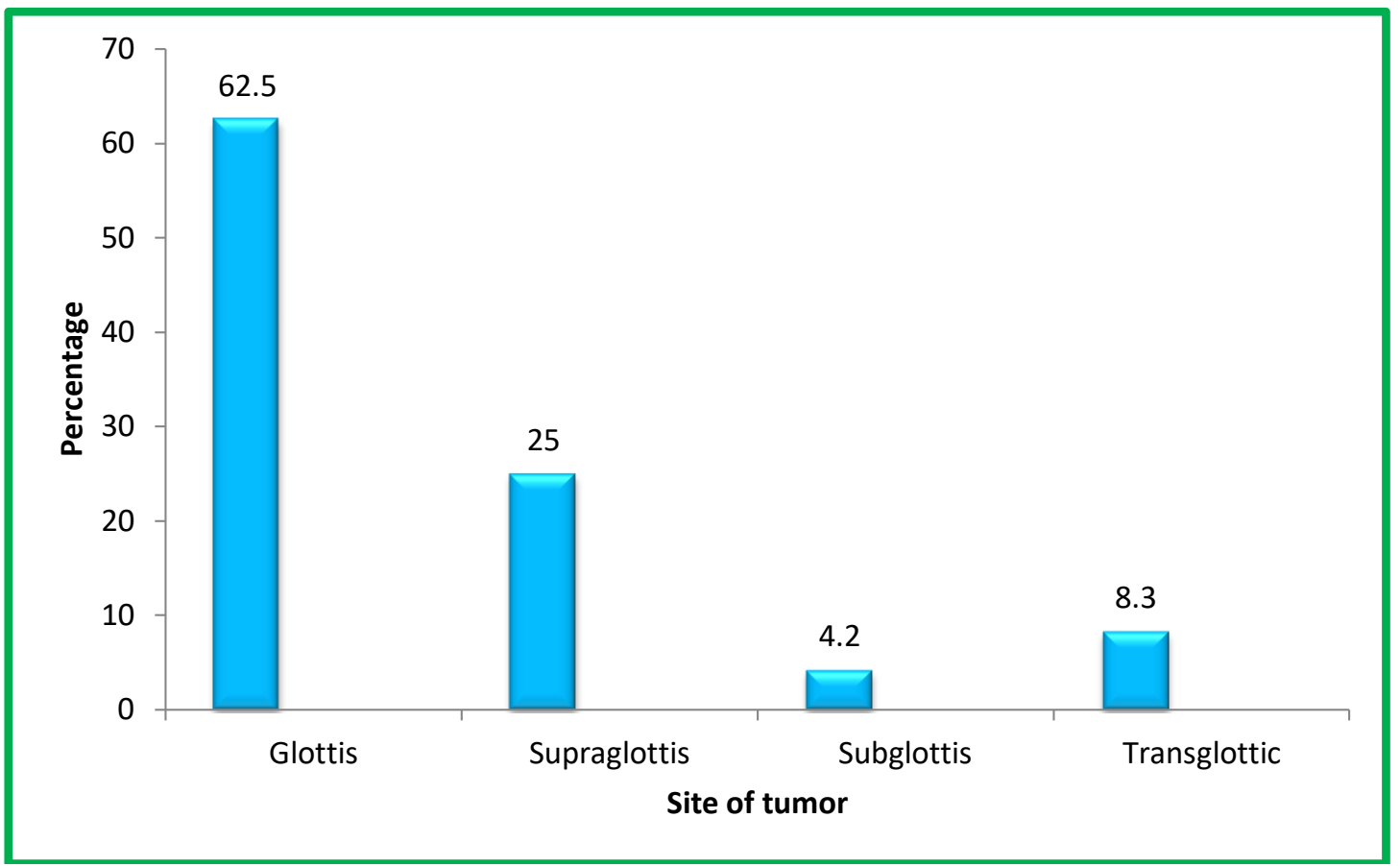

Table 4:-Site of involvement in laryngeal Squamous cell Carcinoma.

The neoplastic lesions were slightly more common on the right side (48.5\%) as compared to left (35.3\%). Bilateral involvement was seen in $16.2 \%$ of neoplastic lesions.

Squamous cell carcinoma was present in $23.5 \%$ cases and was the commonest neoplastic lesion followed by Squamous cell carcinoma in situ (3.4\%), Dysplasia (2.9\%), Giant cell tumor of larynx (0.5\%), Non-Hodgkin's lymphoma $(0.5 \%)$ and Schwannoma (0.5\%).Among malignant laryngeal lesions. Moderately differentiated squamous cell carcinoma was the commonest (66.7\%) followed by well differentiated (14.6\%) and poorly differentiated (8.3\%). Spindle cell carcinoma constituted $10.4 \%$ of cases.(Figure $3,4 \& 5)$ ). The most common site of involvement of laryngeal malignancies was the Glottis (62.5\%) of cases followed by Supraglottis (25\%),Transglottic (8.3\%) and least subglottic region (4.2\%) [Table 4].(Figure $1 \& 2$ )

Out of the 12 laryngectomies, 11 were for laryngeal squamous cell carcinoma and one for laryngeal Giant cell tumor.

Out of the 11 laryngectomies for squamous cell carcinoma, 3 cases showed perineural invasion, 5 cases showed lymphovascular invasion, 3 cases showed no lymphovascular or perineural invasion. 


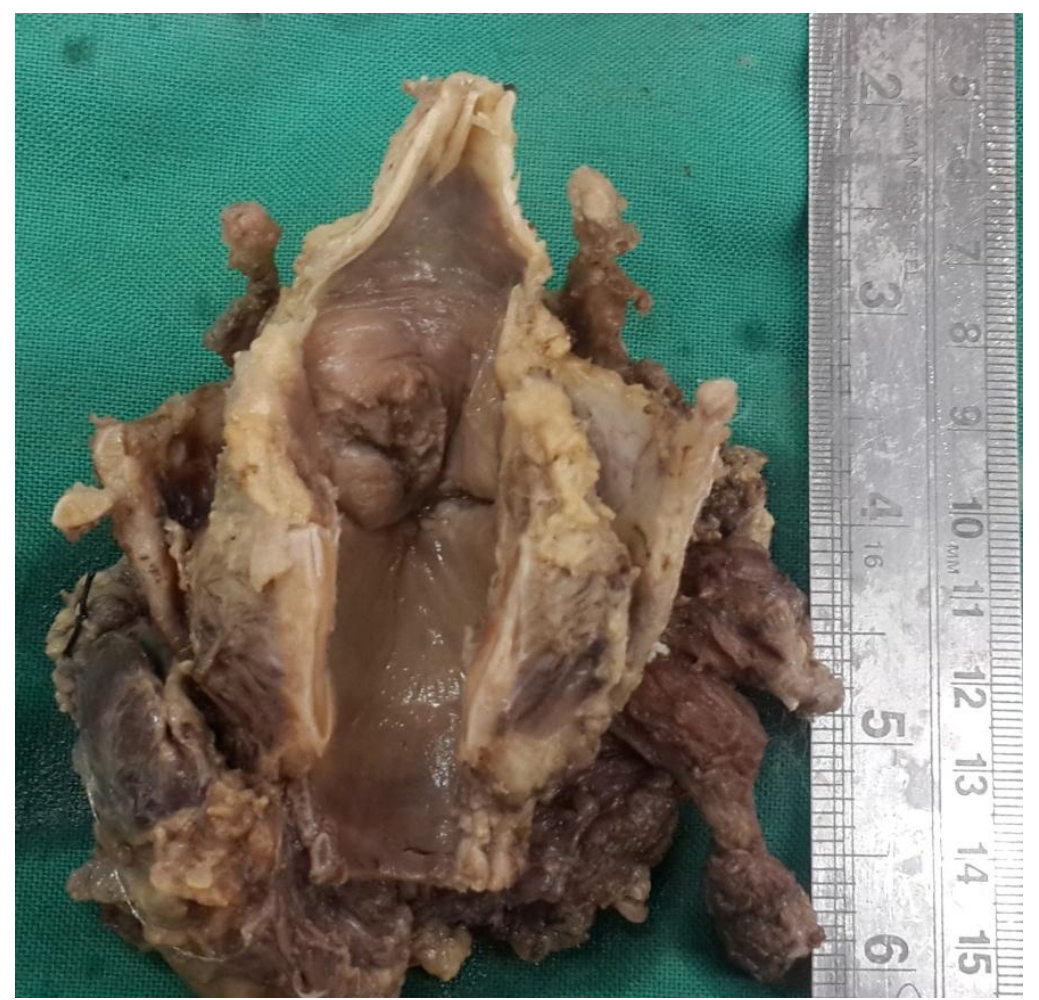

Figure 1:Supraglottic cancer

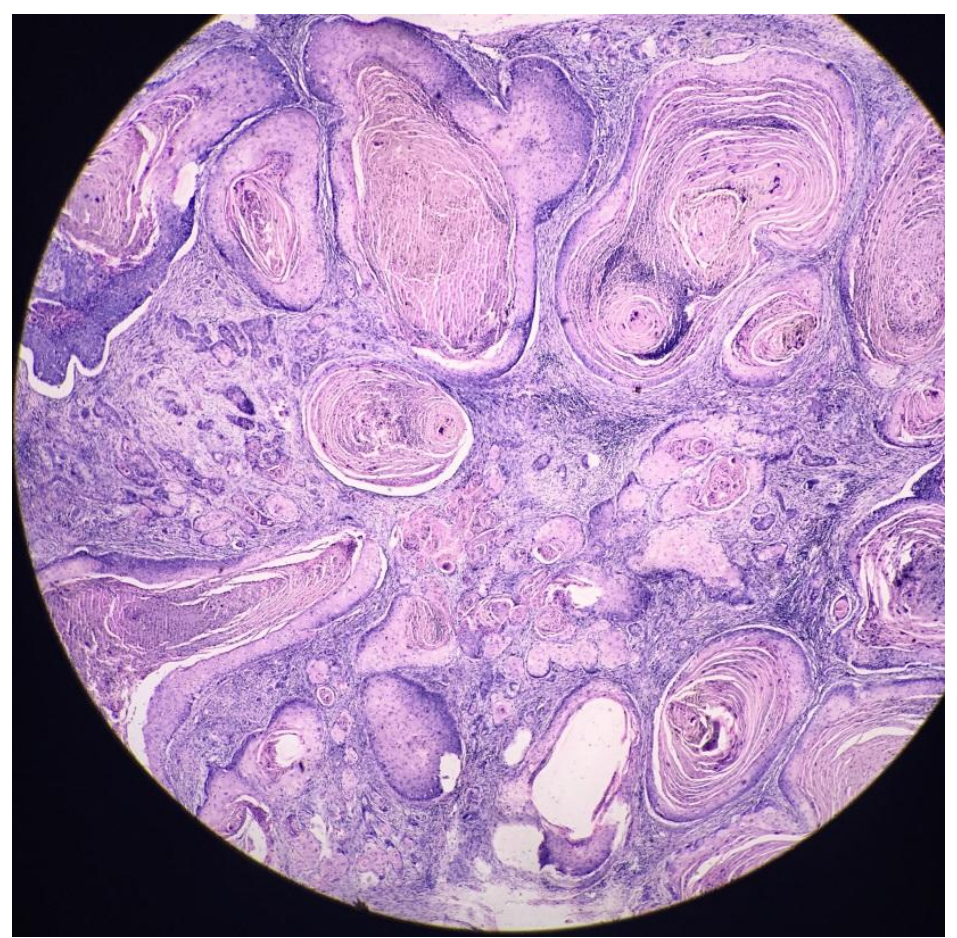

Figure 2:100x Well differentiated Squamous cell carcinoma (H\&E stain)

Out of the laryngectomies for malignant lesions most cases $54.5 \%$ were in stage II. [Table 5] 


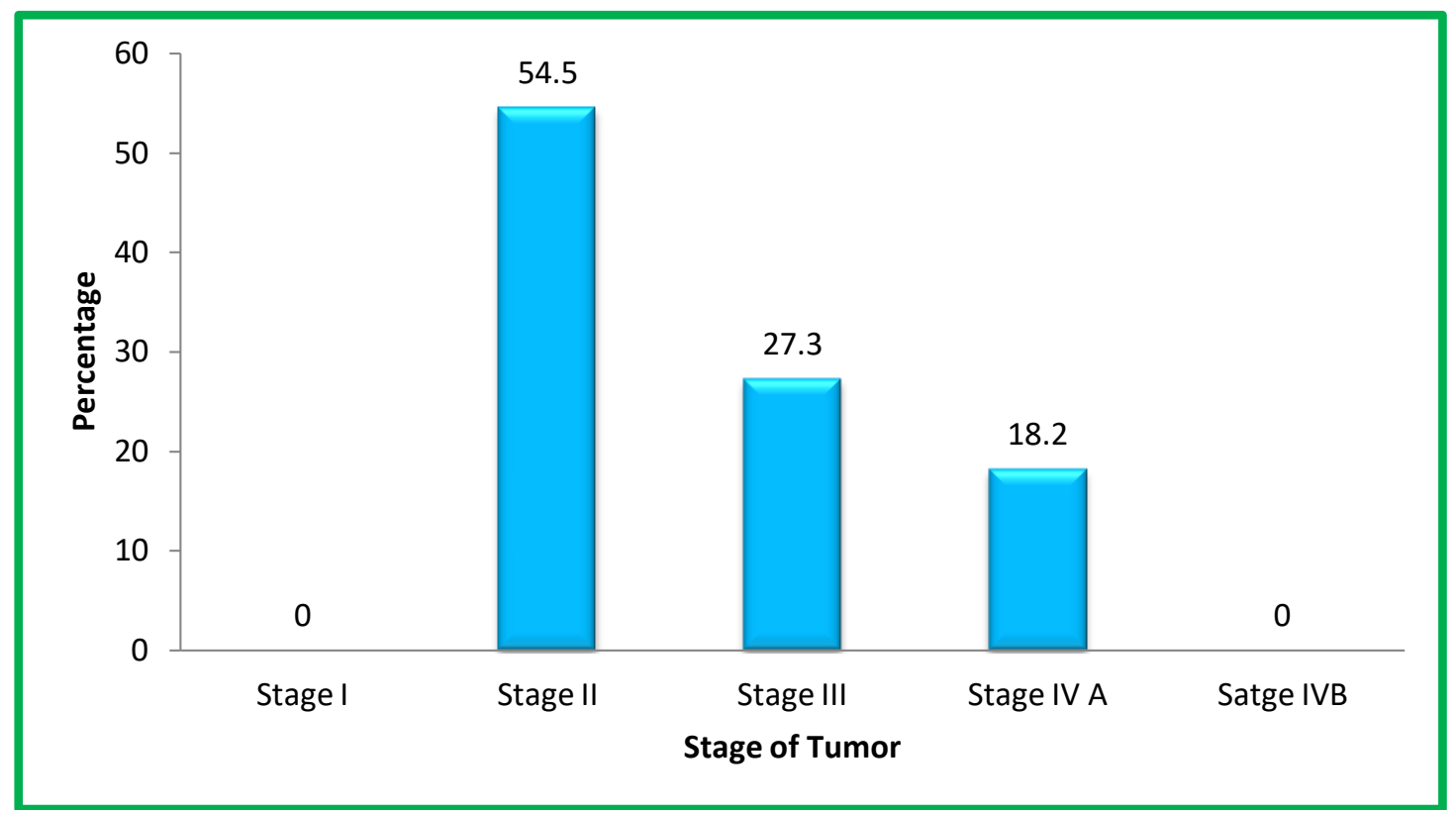

Table 5:-Bar chart showing tumor stage of laryngeal malignancies in laryngectomy specimens

\section{Discussion:-}

Age

The neoplastic lesions showed a peak after 50 years. Most of the cases were in 60-69 year age group (29.4\%) and $>70$ year age group (30.9\%), followed by 50 -59 age group (25\%).Sharma DK et al (2011) found malignant tumors to be common among age group 31-80 years with maximum cases in 40-70 year age group. Ahmad SM et al (2010) found majority of patients with carcinoma larynx were in 5th to 8th decade with peak incidence in 7 th decade in males and 6th decade in females.

\section{Gender}

There was male preponderance in our study. Sharma DK et al $(2011)^{2}$ also found benign and malignant tumors to be common in males as compared to females. They suggested that vocal strain, occupation and smoking and drinking alcohol in the males may have played a role. Shinde KJ et al (2013) 78 cases (90.69\%) were males and 8 cases $(9.3 \%)$ were females.

\section{Distribution of study patients as per residence}

Neoplastic lesions were common in rural areas (64.7\%) compared to urban (35.3\%), similar results were obtained by Sharma DK et al (2011) ${ }^{2}$ and Chaitanya V et al (2015)

\section{Distribution of study patients as per smoking}

In the neoplastic group, $94.1 \%$ were smokers and $5.9 \%$ were non-smokers. Chaitnaya $\mathrm{V}$ et al ${ }^{5}(2015)$ found that among neoplastic lesions, $50 \%$ patients had history of tobacco smoking in the form of cigarette/ beedi. Shinde KJ et al (2013) ${ }^{4}$ showed that 66 out of 86 cases of malignancies had a past history of beedi smoking.

\section{Distribution of study patients according to laterality}

The neoplastic lesions were slightly more common on the right side (48.5\%) as compared to left (35.3\%).Kumar JS et al (2015) found a total of $63.3 \%$ of patients had carcinoma on the left side of the larynx and $36.6 \%$ had carcinoma on the right side, which is in contrast to our study. The predominance on the right side cannot be explained and needs a larger study.

Distribution of study patients according to diagnosis

Squamous cell carcinoma was present in $23.5 \%$ cases and was the commonest neoplastic lesion followed by Squamous cell carcinoma in situ (3.4\%), which is similar to Chaitanya V et al (2015) 
Among laryngeal Squamous cell carcinoma most were moderately differentiated (66.7\%) followed by well differentiated (14.6\%) and poorly differentiated (8.3\%), this is similar to ChaitanyaV et al (2015) 5 and Kumar JS et al $(2015)^{6}$. Out of the laryngectomies for malignant lesions, $54.5 \%$ were in stage II, followed by $27.3 \%$ cases in stage III and $18.2 \%$ case in Stage IV. Stage II tumors were the commonest, which is also reported by Sajad M et al (2002) and Varalakshmi KP et al (2016) but in contrast to Kumar JS et al ${ }^{6}(2015)$, Shinde KJ et al (2013) $)^{4}$ and Markou K et al (2013), who report a greater incidence of Stage III and Stage IV A cancers. Our study showed a preponderance of glottis cancers and hence the early presentation of cancers.

\section{Study of adverse prognostic factors}

Out of the 11 laryngectomies done for squamous cell carcinoma, 3 cases showed perineural invasion, 5 cases showed lymphovascular invasion. 3 cases showed no lymphovascular or perineural invasion.

Iovanescu GH et al (2013) studied 95 patients and found perineural and vascular invasion in 15 patients, perineual invasion was discovered in two (13.33\%), only vascular invasion in five (33.33\%) patients and eight $(53.33 \%)$ patients presented both with perineural and perivascular invasion, which is similar to the current study. They compared these results with relapses and found that cell differentiation degree and vascular invasion as major prognostic factors. Mesolella $\mathrm{M}$ et al (2016) studied 40 patients who had undergone laryngectomy and had perineualinvasion,which included 33 males and 7 females and found that perineural invasion is a valuable prognostic factor that correlates with low survival rate in patients with laryngeal malignancies.

\section{Site of involvement of laryngeal malignancies}

The present study found glottis as the commonest site of laryngeal cancer followed by supraglottis. This finding is similar to Markou K et al $(2013)^{9}$, Chaitanya V et al (2015) $)^{5}$ and Kumar JS et al (2015) ${ }^{6}$

\section{Conclusion}

To conclude, moderately differentiated squamous cell carcinoma is the commonest laryngeal malignancy affecting predominantly males and smokers . Light microscopy and histopathological examination remains the mainstay and gold standard in diagnosing benign and malignant lesions in larynx and studying the adverse prognostic factors.

\section{References:-}

1. Pampori R, Shamas I, Islam S. Distribution of Head and Neck Cancers in Kashmir Valley. The Internet Journal of Head and Neck Surgery 2009; Volume 4, Number 2.

2. Sharma DK, Sohal BS, Bal MS, Aggarwal S. Clinico-pathological study of 50 cases of tumours of larynx. Indian J Otolaryngol Head Neck Surg 2013; 65(Suppl 1): 29-35.

3. Ahmad SM. Carcinoma of Larynx. An epidemiological and Pathological study. Journal of Missan Researches 2010; $7(13)$.

4. Shinde KJ, Hashmi SIH. Clinicopathological Study of Laryngeal Masses. IOSR Journal of Dental and Medical Sciences (IOSR-JDMS). 2015; 14 (1): 61-79.

5. Chaitanya V, Nikethan B. Clinicopathological Study of Non Neoplastic and Neoplastic Lesions of Larynx. Int J Intg Med Sci 2015; 2(12): 200-205.

6. Kumar JS, Bhutia NN, Bhutia TJ, Malik P, Singh M, Devi HP. Malignant Tumors of the Larynx: A Clinicopathological Study of 30 Cases. Middle East Journal of Cancer 2015; 6(2): 71-78.

7. Sajad M, Singh JB, Ali S, Chanda N, Ahmed S, Ahmed M, et al. Cancers of the Upper Aerodigestive tract in Kashmir (A Clinicopathological Study). JK Practitioner 2004; 11(1): 17-20.

8. Varalakshmi KP, Naik VS, Swapna RS, Sravani P, Padmaja MN. Laryngeal Biopsies with Special Reference to Malignant Tumors: A Histopathological Study. Int J Sci Stud 2016; 4(3): 197-202

9. Markou K, Christoforidou A, Karasmanis I, Tsiropoulos G, Triaridis S, Constantinidis et al. Laryngeal cancer: epidemiological data from Northern Greece and review of the literature. Hippokratia. 2013; 17(4): 313-8.

10. Iovanescu GH, Poenaru M, Doros C, Boruga O. Histopathological prognostic and risk factors in patients with laryngeal neoplasms RJMe 2013; 54(4): 1087-1092

11. Mesolella M, Iorio B, Misso G, Luce A, Cimmino M, Iengo M et al. Role of perineural invasion as a prognostic factor in laryngeal cancer. OncolLett 2016; 11(4): 2595-2598. 